Article

\title{
A Concretizing Research on Making Higher-Education Sustainability Count
}

\author{
Muhammet Usak ${ }^{1}$ (D), Ming Yuan Hsieh ${ }^{2, *(\mathbb{D})}$ and Yung-Kuan Chan ${ }^{3}$ \\ 1 Institute of Psychology and Education, Kazan Federal University, 420008 Kazan, Russia; musak@kpfu.ru \\ 2 Department of International Business, National Taichung University of Education, Taichung 403454, Taiwan \\ 3 Department of Management Information Science, National Chung Hsing University, \\ Taichung 402204, Taiwan; ykchan@nchu.edu.tw \\ * Correspondence: cpawisely@mail.ntcu.edu.tw; Tel.: +886-4-2218-8731
}

Citation: Usak, M.; Hsieh, M.Y.; Chan, Y.-K. A Concretizing Research on Making Higher-Education Sustainability Count. Sustainability 2021, 13, 2724. https://doi.org/ $10.3390 /$ su13052724

Academic Editor: Teen-Hang Meen

Received: 26 January 2021

Accepted: 23 February 2021

Published: 3 March 2021

Publisher's Note: MDPI stays neutral with regard to jurisdictional claims in published maps and institutional affiliations.

Copyright: (c) 2021 by the authors. Licensee MDPI, Basel, Switzerland. This article is an open access article distributed under the terms and conditions of the Creative Commons Attribution (CC BY) license (https:/ / creativecommons.org/licenses/by/ $4.0 /)$.

\begin{abstract}
In order to manage the worrying predicament of declining global birth rates, a majority of higher-education institutions have commenced to institute a series of diversified strategies in order to make higher-education sustainability count. The aim of this research is to present the results of a study with the goal of helping educational institutions achieve their sustainability. As a succession of quantitative and qualitative analyses and measurements, there are four valuable and contributive findings in this research. First, total tuition and miscellaneous revenues (TTMR), total university-industry cooperative revenues (TUCIR) and total grants from government (TGG) of higher-education governance (HEG) were able to directly and effectively increase higher-education sustainable value. This definitively indicates that current higher-education students and staff, as well as higher-education experts and professionals, indeed agree that the tuition and miscellaneous fees, university-industry cooperative, and government grant revenues have become the most critical determinants of university environment social governance (UESG). This is because the majority of higher-education institutions do need these revenue resources to advance a succession of environmental protections, social responsibilities, and governance performance for current higher-education institution sustainability development. Second, comprehensive scale of QS rankings (CS-QS) was the most important key determinant to evaluate the university social responsibility development (USRD), which means the majority of higher-education institutions have to pay more attention on the comprehensive scale of QS rankings (CS-QS) in order to make more sustainability count. The third finding is the number of student's publications (NSP), which was the most crucial key determinant to assay return on investments (ROI), meaning current higher-education students, staff, experts, and professionals consent to higher-education institutions having to establish an evaluated system for student's publications to stimulate students to publish their diversified studying outcomes in order to make students recognize their growth after taking courses in higher education. The last finding is total tuition and miscellaneous revenues (TTMR) was the most momentous key determinant to control high education governance (HEG), which means current higher-education students, staff, experts, and professionals are concerned with the various governance performances of their tuition and miscellaneous fees. As for the future direction, there are still some evaluated criteria and assessed methods to be comprehensively considered and employed for inducing in-depth conclusions and findings with higher research reliability and validity without time limitations and resource restrictions.
\end{abstract}

Keywords: university social responsibility (USR); social returns on investment (SROI); environment social governance (ESG); university environment social governance (UESG); factor analysis (FA); analytical network process (ANP)

\section{Introduction}

According to the global total fertility rate (TFR) development predicted report of United Nations in 2020, many nations have entered into a period of declining population 
growth rates, with the majority of them located in Asia (Japan, South Korea, and Thailand) and eastern and western Europe (Spain and Italy). It is projected that the global population of people over 80 years old will increase six-fold by 2100 as a result of rapid medical advancement in science and technology. Consequently, many governments have to confront the critical issues that result from declining population growth rates such as [1] economic recessions [2], government fiscal deficits [3], declining education industries declining, and so forth. According to the 2020 official report of the National Policy Foundation in Taiwan, the Taiwanese population amounted to $23,600,000$ people, which is a historical high peak. The numbers of newborn babies in 2020 was only approximately 16,500, which was for the first time lower than the number of deaths. By following this developed tendency, the over-65-years population is going to be 25 percent of the entire Taiwanese population in 2030, which means that Taiwan is going to march toward the period of a lower birthrate and an aging population. As a negative consequence of negative-growth birthrate, the employed population was $16,830,000$ in 2020, which was lower than $17,737,000$ at the climax of Taiwan's employed population in 2015. Significantly, according to the latest annual largescope report from the Ministry of Labor for investigating changing jobs and those willing to work overseas, not only are approximately 737,000 Taiwanese working in transoceanic jobs, but up to $87.8 \%$ of 3000 Taiwanese interviewees are also willing to continue applying to overseas positions in Japan, America, and countries in ASEAN (the Association of Southeast Asian Nations). This implies that an estimated 7,360,000 Taiwanese of 8,380,000 current Taiwanese labors are willing and planning to apply the various overseas job vacancies. The top five preferred countries for Taiwanese are Japan (27.3\%), America (17.9\%), Australia $(12.8 \%)$, ASEAN $(10.3 \%)$, and Europe $(9.7 \%)$. In particular, after an in-depth analysis of their motivation for applying to transoceanic jobs, the most important factor for applying to transoceanic jobs is that the average overseas salary is 2.12 times of Taiwanese average Taiwan employment salary [4-6]. Furthermore, according to the latest annual report from the Ministry of Economy that surveyed the top 50 Taiwanese companies, they have the desire to improve their employees' various employability to completely solve diversified problems in order to effectively and efficiently assist the corporate profitable developments and beneficial updating. Therefore, in order to break through the negative consequences of a negative-growth birthrate, most higher-education institutions have to not only increase their traditional academic reputation but also advance their image and the identification of the entire society by following and being aware of public social responsibility [7]. Highereducation institutions are not only requested to pursue traditional educational duty but also called on for taking social responsibilities for concrete environmental protection and abstract social benefits [8].

A comprehensive search of related research [9-13] in the fields of current environmental protection and abstract social benefits did not uncover one that was able to thoroughly and concretely assay the dual impacts of concrete environmental protection and abstract social benefits to contemporary higher-education institutions from the three analytical perspectives employed in this research. As a result, in order to resupply this vast research gap, this research cross-consolidated the 17 sustainable development goals (SDGs) of university social responsibility (USR) [14], the statistic measurability of social returns on investments (SROI) [14], and sustainable investment flexibility of environment, social, and government (ESG) to creatively form and systematically develop the most modern universityenvironment, social, and government (U-ESG) [15]. Specifically, to strengthen research validity, reliability, credibility, and representativeness, this research also crossemployed the factor analysis (FA) systematic approach of quantitative analysis and the analytical network process (ANP) hierarchical model of quantitative analysis to establish the most effective and efficient evaluated model of U-ESG in order to directly induce the most critical determinants of U-ESG to effectually enhance the higher-education-developed sustainability. The principal goal of this research is to consolidate the 17 SDGs of USR and the statistical measurability of SROI $[16,17]$ and ESG to successfully develop U-ESG [18] for the purpose of developing higher-education sustainability by making higher-education institutions con- 
cretely advance internal institutional performance and external environmental protection as well as abstractly enhance social benefits as demonstrated in Figure 1.

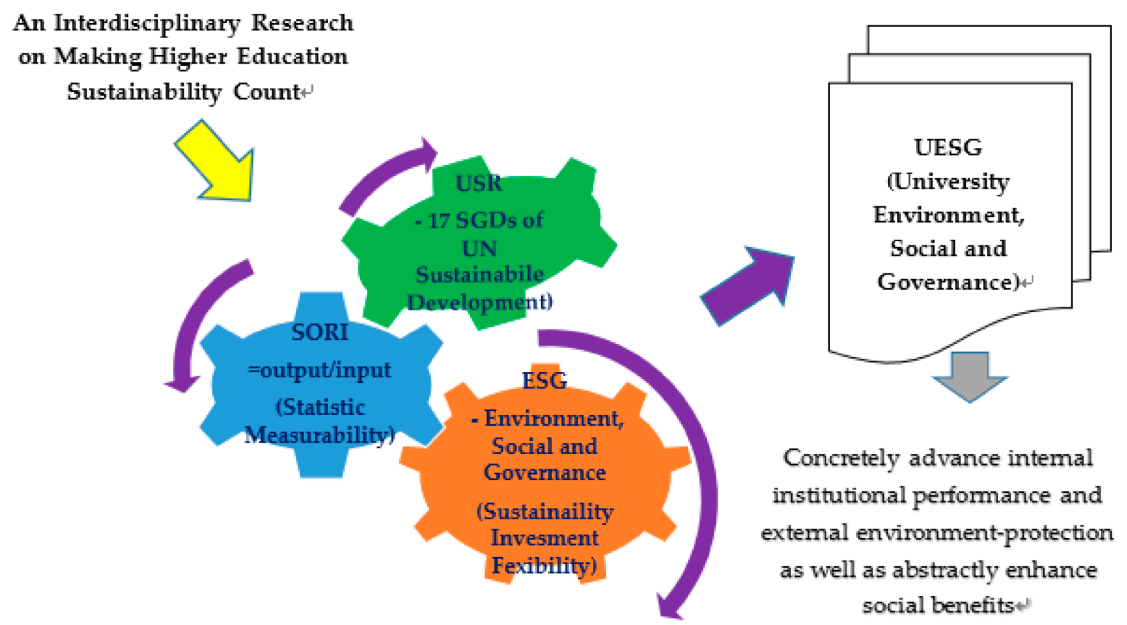

Figure 1. Comprehensive research concept.

\section{Literature Reviews}

\subsection{Literature on Main Modern Concepts}

Especially, in association with Figure 1, the 17 SDGs of USR, the statistic measurability of SROI, sustainable investment flexibility of ESG, and U-ESG, along with, in statistics, the FA systematic approach of quantitative analysis and ANP hierarchical model of qualitative analysis, were cross-employed in a succession of evaluated measurements. Therefore, the theoretical concept of USR, SORI, and ESG as well as assessed statistical methods of the FA systematic approach and ANP hierarchical model were discussed in this session.

\subsubsection{University Social Responsibility (USR)}

As for the initial concept of USR, USR was induced in the corporate social responsibility (CSR), and the most momentous notion of CSR is "Taking from Society; Using in Society", because a company is not only pursuing the corporate profits and managerial performance but also promoting the social benefits, including environmental protection and socially developed sustainability [19]. In the 1970s, the most important idea of CSR was to pursue the maximized profits for corporate shareholders; however, following a couple of economic recessions and global financial crises, the natural world has confronted lots of damages resulting from the development of the majority of international companies. Currently, a bulk of international companies have more capital and resources than some national governments, which means these huge companies should not only provide recruiting opportunity and corporate property but also create much more social benefits for all of humanity [20]. As a social citizen, companies have to directly take social responsibilities to increase and create social benefits for all of humanity. With respect to the explanation of CSR, each higher-education institution is also one of social citizens; they have to not only take educational diligences but also take responsibilities for enhancing the benefits for the entire society in order to obtain more social identity for creating sustainable development [21]. As a result, following the awareness of USR, the majority of higher-education institutions have started to look squarely at more social requirements in covering diversified aspects because most people have agreed that the briefest revenues and resources for higher-education institutions resulted from the government, such as educational grants and research compensation [22]. With rapid development and advocacy of USR, more academic scholarship and empirical professionals of USR have to start to induce the 17 sustainable development goals (SDGs), stated from the department of Economic and Social Affairs Sustainable Development of United Nations in 2015. Continuously, these 17 sustainable development goals ("SDGs") of USR have categorized their considered factors into three 
aspects: (1) the economic growth aspect covers the considered factors such as promoting green energy (PGE) and employment and sustainability economy (FEE); (2) the social progress aspect consists of the considered factors such as the diminishing poverty (DP), promoting food and agriculture (PFA), advancing health and wellbeing (AHW), enhancing quality education (EQE), making gender more equal (MGME), endeavoring equity rights (EER), and partnerships for the foals (PG); and (3) the environmental protection aspect contains the considered factors such as the strengthening water quality and hygiene (SWQH), facilitating, forcing industrial infrastructure innovation (FIII), promoting sustainable cities and communities (PSCC), environmental and climate action (ECA), life below water (LBW), and life on land (LL).

\subsubsection{Social Return on Investments (SROI)}

The majority of companies have taken a bulk of noncommercial activities of CSR, and then they have started to consider the various measurements of these activities in order to comprehensively assess and manage these activities for exposing the positive influence of these activities to companies and the entire society. For this reason, SROI was created from the consolidation of the social benefits of CSR and return on investments (ROI) of traditional financial management [23]. As for the origins of SROI, SROI concepts inductively originated from the traditional financial return on investments, and specifically, SROI focuses more on the nonfinancial potential returns and benefits, including social impact, environmental sustainability, humanity development, etc. Therefore, SROI measures the tangible and intangible returns, benefits, and value (such as economic returns, social impact benefits, and environmental value) of an organization or institution through a series of diversified measured indicators [24]. Significantly, the calculations of SROI were based on the rate or ratio between inputs and outputs.

\subsubsection{Environment, Social, and Governance (ESG)}

As for the initial concept of ESG, ESG was mentioned in the 2004 official report of United Nations Global Compact to provide a series of the briefly invested standards of the principles for responsible investment principles (PROP) for most of business investors and commercial analysts [25]. Significantly, ESG has been currently applied for evaluating the corporate sustainability investment flexibility in many famous assessed companies and associations. These are (1) Morgan Stanley Capital International (MSCI) which is a global provider of equity, fixed income, hedge fund stock-market indexes, multi-asset portfolio analysis tools, and ESG products by means of publishing the MSCI BRIC, MSCI World, and MSCI EAFE Indexes, located in New York City, United States; (2) Morningstar, which is an American financial services to offer an array of investment research and investment management services, located in Chicago, Illinois, United States since 1984; and (3) the Sustainability Accounting Standards Board (SASB). In detail, the environment (E) session briefly covers corporate energy saving, corporate conservation of natural resources, corporate animal protection, treatment plans [26], etc. The social (S) session primarily consists of stakeholder's relationships, suppliers' management, corporate donation plans, employees' take-care policies, employees' volunteer projects, social benefit's policies, etc. [27]. Lastly, the governance $(G)$ session focuses on not only traditional corporate profits and performance but also the conflicts of interest of professional managers and board members as well as corporate illegal practices, etc. Specifically, in the wake of broad consumers' awareness on environmental protection and social benefits, it is definite and predictable that ESG has become the corporate investment evaluation mainstream because of the higher ESG index and the higher sustainability flexibility [28].

\subsection{Assessed Statistic Methods}

\subsubsection{Factor Analysis of Quantitative Analysis}

In contemplation with higher research representativeness and validity in the evaluated measurements of large-scale surveyed questionnaires, the FA systematic approach 
of quantitative analysis was induced to identify and refine the key determinant through reducing the analyzed factors by means of measurements of communities and connections among each appraised criterion. The essential computation of FA systematic approach of quantitative analysis estimated the weights between the dependent variables (direct observed impact-measured factors) defined as $Y\left(y_{1}, y_{2}, \ldots, y_{k}\right)$ and the independent variables (direct unobserved influenced factors) presented as $X\left(x_{1}, x_{2}, \ldots, x_{k}\right)$. Continuously, the weighted constants $W\left(W_{i j}\right)$ between the dependent variables and independent variables was computed as Equation (1) [29] as

$$
X_{1}=\lambda_{11} Y_{1}+\lambda_{12} Y_{2}+\ldots+\lambda_{1 k} Y_{k}
$$

s.t. 1: $Y_{-}=P^{1} X_{-}, X_{-}=P^{1} Y_{-}$

s.t. 2: standardize intersection of variance to be 1 (Maximum).

If maximization:

$$
X_{k}-u_{k}=\lambda_{k 1} f_{1}+\lambda_{k 2} f_{2}+\ldots+\lambda_{k m} f_{m}+e_{k}\left(\text { s.t. }(X-u)_{-k \times 1}=\wedge_{m_{k \times m}} f_{m \times 1}+e_{-k \times 1}\right) .
$$

Variance-covariance matrix presents as

$$
\sum=\wedge \Phi \wedge^{1}+\Psi, \Psi=\operatorname{diag}\left(\Psi_{1}, \Psi_{2}, \ldots, \Psi_{m}\right)\left(\text { s.t. } \Phi=I_{m \times m}\right)
$$

\subsubsection{Analytical Network Process of Qualitative Analysis}

In order to strengthen the research accuracy and reliability to identify the positive cause and effect between each assessed criterion, the authors of [30] pioneered the analytical hierarchy process ("AHP") for analyzing the single-way research topic and question. As following the research questions has become more complicated, the authors of [31] induced a succession of analytical hierarchical for forming ANP hierarchical model to not only handle the assessed measurements of the positive cause and effect but also analyze the interactive dependences and correlation among each assessed criterion to thoroughly and extensively discover the most suitable solutions for these complicated research questions through positive reciprocal matrix, pairwise compared matrix, and a comprehensive supermatrix of experts and professionals weight questionnaires. Considering the measured equation, A. matrix of pairwise comparison was chosen in order to obtain the best decision making. The initial concept of A. matrix of pairwise comparison is expressed as the following measured matrix:

$$
\text { A. }=\left(\begin{array}{ccccc}
1 & \cdot & a_{1 j} & \cdot & a_{1 n} \\
\cdot & \cdot & \cdot & \cdot & \cdot \\
a_{i 1} & \cdot & a_{i j} & \cdot & a_{i n} \\
\cdot & \cdot & \cdot & \cdot & \cdot \\
a_{n 1} & \cdot & a_{n j} & \cdot & 1
\end{array}\right)_{n \times n}=\left(\begin{array}{ccccc}
W_{1} / W_{1} & \cdot & W_{1} / W_{j} & \cdot & W_{1} / W_{n} \\
\cdot & \cdot & \cdot & \cdot & \cdot \\
W_{i} / W_{1} & \cdot & W_{i} / W_{j} & \cdot & W_{i} / W_{n} \\
\cdot & \cdot & \cdot & \cdot & \cdot \\
W_{n} / W_{1} & \cdot & W_{n} / W_{j} & \cdot & W_{n} / W_{n}
\end{array}\right)_{n \times n}
$$

In the measured matrix, the measured weights were expressed as $W_{j}$ and the pairwise ratio described as $W_{i} / W_{j}$ in pairwise compared matrix. Subsequently, there are three kinds of characteristics in this A. pairwise compared matrix: (1) $a_{i j}=W_{i} / W_{j} ;(2) a_{i j}=1$, for $I=j, a_{i j} \times a_{j i}=1$. As a result, the relative pairwise weights $\left(W\left(W=\left[W_{1}, \ldots, W_{j}, \ldots, W_{n}\right]\right)\right.$ and the local priority vector $w$ (eigenvector) were able to be calculated by the vector quantities method $(\mathrm{AW}=n W)$ resulted from the inductive principle $\left(\mathrm{AW}=\lambda_{\max }\right)$, and the priority vector and maximized eigenvalue were computed by measurements of $A$. matrix of pairwise compared matrix. As for testifying the consistence of ANP hierarchical model of qualitative analysis, the two-stage algorithm is presented in Equation (2).

$$
R w=\lambda_{\max } w ; w_{i}=\sum_{j=1}^{m}\left(R i j / \sum_{i=1}^{m} R i j\right) / m
$$


Continuously, the consistency index (C.I.) is able to apparently compute in each pairwise compared matric, and the consistency ratio (C.R.) is further able to obviously computed with C.I. and random index (R.I) obtained from the statistic table of random index figure, which are expressed in Equation (3)

$$
\text { C.I. }=\left(\lambda_{\max }-n\right) /(n-1) ; C . R .=\text { C.I. } / \text { R.I. }
$$

As the most important flexibility of ANP hierarchical model of qualitative analysis, the numbers of the C.R. of each pairwise compared matric have to be lower than 0.1 which means there is the higher evaluated consistency in each pairwise compared matrix.

\section{Research Design}

\subsection{Questionnaire Collection}

In order to increase the research validity, reliability, credibility and representativeness, the 120 interviewed participants ( 40 current higher-education students, 40 higher-education staff, and 40 Taiwanese adults) were surveyed by using the 5 -Likert's scale questionnaire for measuring 29 assessed criteria (the 9 appraised criteria of technology education, 10 assessed criteria of students' employability, and 10 SDGs evaluated criteria of USR). Continuously, the two-way positive and negative 5-Likert's scale was further applied in the pairwise comparisons of the questionnaire data for synthetically inducing the most critical determinants of UESG for advancing the higher-education developed sustainability.

\subsection{Questionnaire Interviewees}

As concerns regarding advancement of research reliability, representativeness, and exactitude, the 40 current higher-education students, 40 higher-education staffs, and 40 Taiwanese adults were randomly interviewed for the systematic measurements of FA systematic approach of quantitative analysis. These 120 questionnaires were collected by a random and in-person interview, and these 120 interviewees were representative of the Taipei (northern region), Taichung (western region), Kaohsiung (southern region), and Hualien (eastern region) areas in Taiwan. In addition to research validity and credibility on the ANP hierarchical model of qualitative analysis, 15 professional experts were interviewed in person for a series of pairwise compared matrix. These 15 professional experts covered three groups. The first group included five professional experts (three professors and two scholars) with over 3 years of research experience in the USR development fields. The second group involved five professional experts with over 5 years' work experience in evaluation performance with return on investment. The final group comprised of five professional experts with over 10 years' experience in the research field of higher-education governance.

\subsection{Main Research Criteria}

Based on Figure 1, the original concepts of ESG presents the three major perspectives [32]: environment, social, and governance. Therefore, this research has creatively consolidated the 17 SGDs of UN sustainable development of USR and quantitative measurements of SORI in order to comprehensively form the modern U-ESG. With reference with the authors' previous work, annual official reports of Taiwanese Ministry of Education, and the 2020 Taiwanese best university investigation of high-reputation professional magazine, Global Views Monthly, in Taiwan, there are 27 measurable appraised indicators to be integrated and then refined. Continuously, these 27 quantitative appraised indictors contain three brief aspects: (1) the governance aspect includes the percentage of registration students (PRS), staff-student ratio (SR), teacher-pupil ratio (TR), comprehensive scale of QS rankings (CS-QS), comprehensive scale of THE rankings (CS-THE), comprehensive scale of ARWU rankings (CS-ARWU), and comprehensive scale of CWTS rankings (CS-CWTS); (2) the social impacts aspect embraces the numbers of university social responsibility from government supplements (NUSRGS), numbers of faculty's government research project grant (NFGR), numbers of student's government research project 
grant (NSGR), numbers of faculty's competitions (NFC), numbers of faculty's publications (NFP), numbers of student's competitions (NSC), numbers of student's publications (NSP), numbers of domestic university-college cooperative project (NDUCP), numbers of international university-college cooperative project (NIUCP), numbers of international cooperative university-college (NICU), and numbers of international exchange students (NIES); as well as (3) the financial outcomes aspect comprising the average self-financing for students (ASS), total grants from government (TGG), total government research compensation (GRC), total tuition and miscellaneous revenues (TTMR), total research subsidies of faculty's (TRSF), total university-industry cooperative revenues (TUCIR), total onlinecourses revenues (TOR), total adult's education revenues (TAER), total university-industry cooperative project revenues (TUCPR), and total patent revenues (TUCR).

\subsection{Main Research Process}

Specifically, with respect to Figure 1, each assessed criterion of USR, SROI, and ESG was systematically cross-employed for the in-depth establishing of the most effective and efficient evaluation model of UESG in the main research framework as Figure 2 [33].

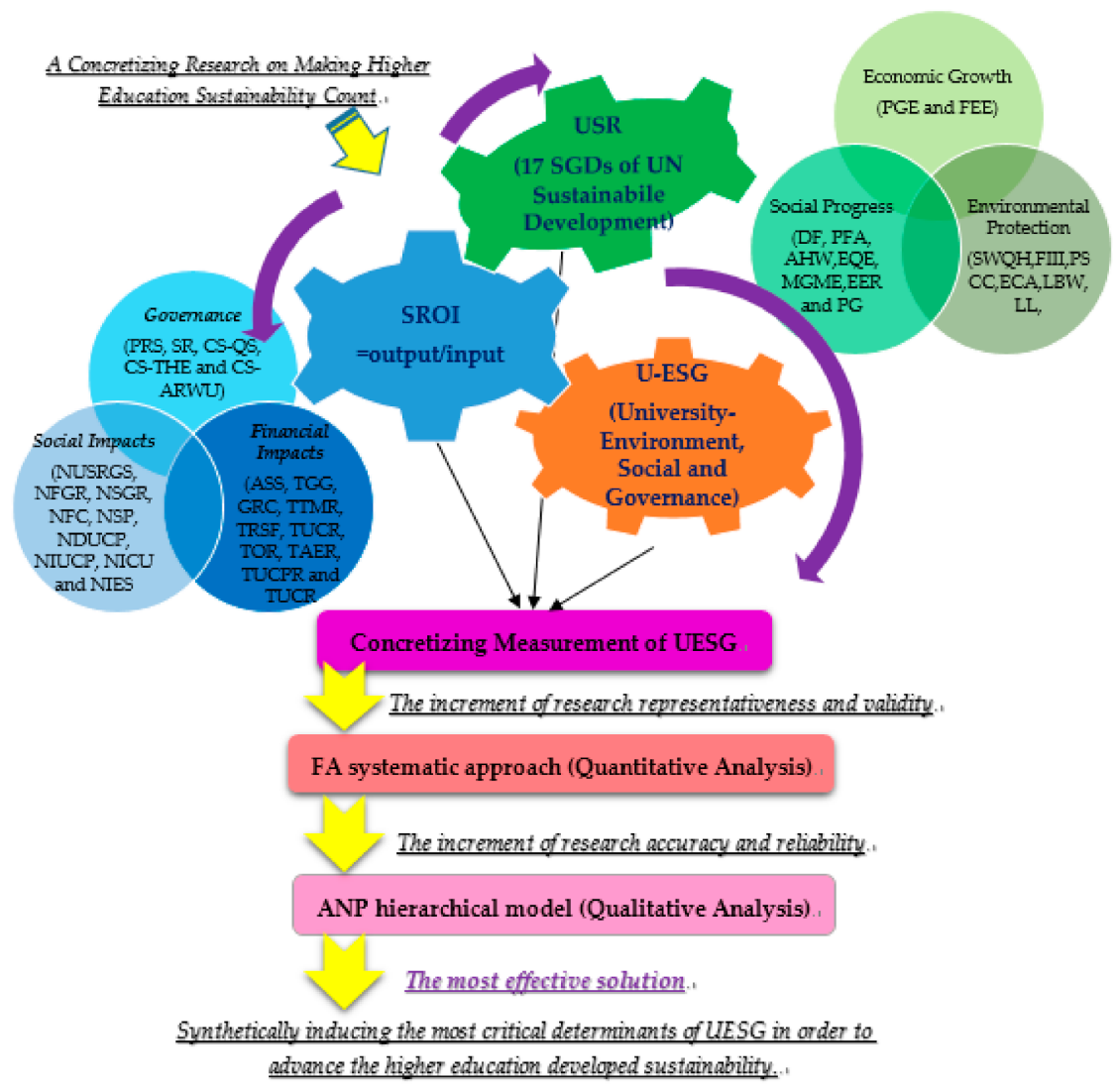

Figure 2. Main research evaluation framework.

\section{Research Measurements}

\subsection{FA Systematic Approach of Quantitative Analysis}

Based on the equation of FA systematic approach, the entire 120 weighted questionnaires were designed to collect data by the means of random selection. Specifically, 113 out of 120 questionnaires were deemed valid or a valid retrieval rate of $94.17 \%$. The descriptive statistic of these 113 valid weighted questionnaires is presented in Table 1. 
Table 1. The descriptive statistic of factor analysis (FA) systematic approach of quantitative analysis.

\begin{tabular}{|c|c|c|c|c|c|}
\hline \multirow{2}{*}{$\begin{array}{c}\text { Gender } \\
\text { Geography }\end{array}$} & \multicolumn{3}{|c|}{ Male: 59 (52.21\%) } & \multicolumn{2}{|c|}{ Female: 54 (47.79\%) } \\
\hline & $\begin{array}{c}\text { Northern Taiwan }{ }^{1} \text { : } \\
35(30.97 \%)\end{array}$ & \multicolumn{2}{|c|}{$\begin{array}{c}\text { Middle Taiwan }{ }^{2} \text { : } \\
38(33.63 \%)\end{array}$} & \multirow{2}{*}{$\begin{array}{c}\text { Southern Taiwan }{ }^{3} \text { : } \\
31(27.43 \%) \\
\text { College: } \\
46(40.71 \%)\end{array}$} & \multirow{2}{*}{$\begin{array}{c}\text { Eastern Taiwan } \\
9(7.97 \%) \\
\text { Graduate: } \\
18(15.93 \%)\end{array}$} \\
\hline $\begin{array}{c}\text { Education } \\
\text { Background }\end{array}$ & $\begin{array}{l}\text { Elementary: } \\
2(1.77 \%)\end{array}$ & $\begin{array}{c}\text { Junior High School: } \\
4(3.54 \%)\end{array}$ & $\begin{array}{l}\text { Senior High } \\
\text { School: } \\
43(38.05 \%)\end{array}$ & & \\
\hline \multicolumn{2}{|c|}{ Have you known USR before? } & \multicolumn{2}{|c|}{ Yes: $78(69.03 \%)$} & \multicolumn{2}{|c|}{ No: 35 (30.97\%) } \\
\hline \multicolumn{2}{|c|}{ Have you known SROI before? } & \multicolumn{2}{|c|}{ Yes: $107(94.7 \%)$} & \multicolumn{2}{|c|}{ No: $6(5.3 \%)$} \\
\hline \multicolumn{2}{|c|}{ Have you known ESG before? } & \multicolumn{2}{|c|}{ Yes: 109 (96.46\%) } & \multicolumn{2}{|c|}{ No: $4(3.54 \%)$} \\
\hline
\end{tabular}

According to Equation (1) of FA systematic approach of quantitative analysis, not only the appraised Kaiser-Meyer-Olkin measure of sampling adequacy was 0.8103 , which was higher than 0.7, but the assessed numbers of significance of the Kaiser-Meyer-Olkin measure and Barlett test of was also $0 \ldots \ldots$, which was lower than 0.05 in Table 2. Obviously, the FA approach was definitely applied to measure the valid questionnaire results of these 113 completed questionnaires.

Table 2. The Kaiser-Meyer-Olkin and Bartlett's Test of FA approach.

\begin{tabular}{lcc}
\hline \multicolumn{2}{c}{ Kaiser-Meyer-Olkin Measure of Sampling Adequacy } & 0.8103 \\
\hline \multirow{3}{*}{ Bartlett test of sphericity } & Chi-squared test & 920.273 \\
& Significance & 351 \\
& Sf & $0 \ldots \ldots$ \\
\hline
\end{tabular}

Summarily, Table 3 expresses the commonality of each evaluated criterion in FA systematic approach of quantitative analysis and in detail, CS-QS (0.808), CS-THE (0.795), and CS-ARWU (0.783) of the governance aspect of ESG; NFC (0.736), NSC (0.759), NSP (0.807), and NDUCP (0.747) of social impacts aspect of ESG as well as ASS (0.717), TGG (0.767), TTMR (0.756), TRSF (0.739), TUCIR (0.751), TOR (0.728), and TAER (0.701) of financial outcomes aspect of ESG were higher than 0.7, which means these 14 assessed criteria had lower explained correlations with the research topic and goal. As a result, the 15 original evaluation criteria were not only refined but also reduced from original measurable factors of ESG by implementing the large-scale questionnaires measurements of FA systematic approach of quantitative analysis in Table 3.

Table 3. The commonality of each assessed criterion in the FA approach.

\begin{tabular}{ccc}
\hline Criteria & Initial & Extraction \\
\hline PRS & 1 & 0.659 \\
\hline SR & 1 & 0.44 \\
\hline TR & 1 & 0.683 \\
\hline CS-QS & 1 & 0.808 \\
\hline CS-THE & 1 & 0.795 \\
\hline CS-ARWU & 1 & 0.783 \\
\hline CS-CWTS & 1 & 0.666 \\
\hline NUSRGS & 1 & 0.628 \\
\hline
\end{tabular}


Table 3. Cont.

\begin{tabular}{ccc}
\hline Criteria & Initial & Extraction \\
\hline NFGR & 1 & 0.637 \\
\hline NSGR & 1 & 0.61 \\
\hline NFC & 1 & 0.736 \\
\hline NFP & 1 & 0.582 \\
\hline NSC & 1 & 0.759 \\
\hline NSP & 1 & 0.807 \\
\hline NDUCP & 1 & 0.747 \\
\hline NIUCP & 1 & 0.594 \\
\hline NICU & 1 & 0.688 \\
\hline NIES & 1 & 0.575 \\
\hline ASS & 1 & 0.717 \\
\hline TGG & 1 & 0.767 \\
\hline GRC & 1 & 0.618 \\
\hline TTMR & 1 & 0.756 \\
\hline TRSF & 1 & 0.739 \\
\hline TUCIR & 1 & 0.751 \\
\hline TOR & 1 & 0.728 \\
\hline TAER & 1 & 0.701 \\
\hline TUCPR & 1 & 0.683 \\
\hline TUCR & 1 & 0.487 \\
\hline
\end{tabular}

\subsection{ANP Hierarchical Model of Qualitative Analysis}

After conducting FA systematic approach of quantitative analysis, in association with the Equations (2) and (3), the ANP hierarchical model of qualitative analysis was applied to thoroughly assay the 15 weight questionnaires of 15 experts and professionals in order to comprehensively discuss and explore the interactive dependences and correlations among each 15 assessed criteria that were refined from FA systematic approach of quantitative analysis. The evaluated process of ANP hierarchical model of qualitative analysis has been constructed in Figure 3. Particularly, according to the essential concepts and characteristics of USR, SROI and ESG, governance performance (GP), social impacts (SI), and financial outcomes (FO) have been categorized assessed criteria. Significantly, the 15 major factors refined from the FA systematic approach of quantitative analysis have been classified as the evaluated sub-criteria from three analytical perspectives: USR Development ("USRD"), ROI, and higher-education governance (HEG). This was done to comprehensively analyze the three candidates, negative sustainability count (NSC), non-impact sustainability count (NISC), and positive sustainability count (NPC) according to the characteristics of surveyed experts. 


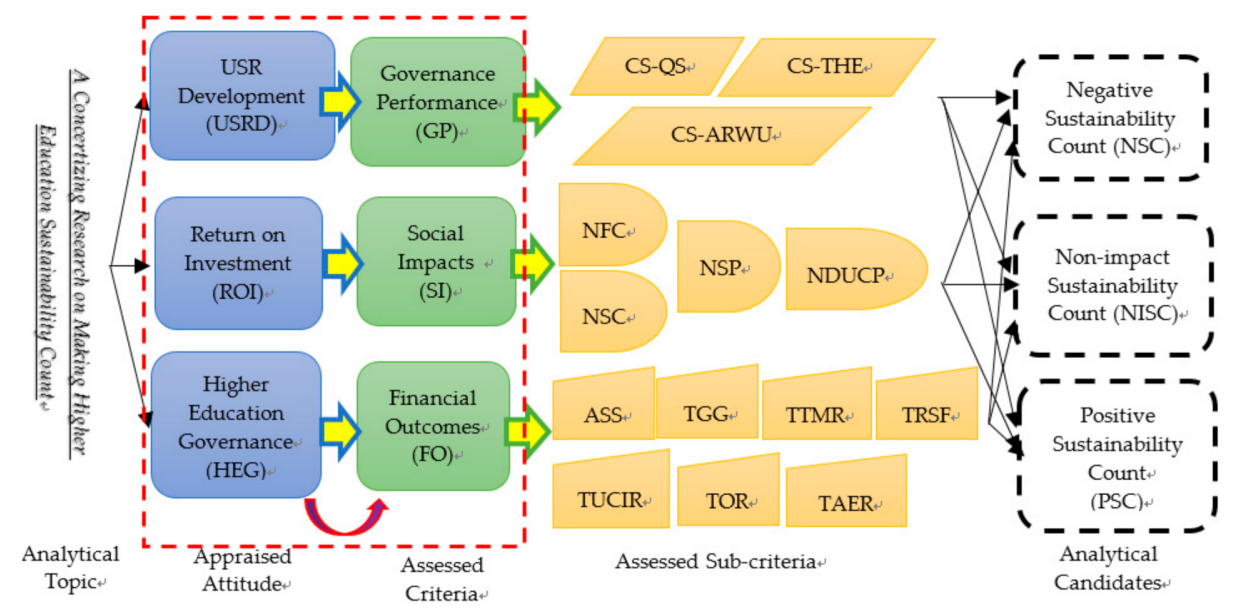

Figure 3. Evaluated process of analytical network process (ANP) hierarchical model of qualitative analysis.

Subsequently, all the numbers of C.I. and C.R. of each pairwise compared matric were expressed in Table 4, and the entire C.R. of each pairwise compared matric were definitely lower 1, which means the consistence of each attitude, assessed criterion, sub-criterion, and candidate were higher for the research topic.

Table 4. The commonality of each assessed criterion in the FA approach.

\begin{tabular}{|c|c|c|}
\hline & C.I. & C.R. \\
\hline USRD & 0.0569 & 0.098 \\
\hline ROI & 0.0576 & 0.0994 \\
\hline HEG & 0.0525 & 0.0906 \\
\hline GP & 0.0556 & 0.0959 \\
\hline SI & 0.0527 & 0.0908 \\
\hline $\mathrm{FO}$ & 0.0529 & 0.0913 \\
\hline CS-QS & 0.0532 & 0.0917 \\
\hline CS-THE & 0.0499 & 0.086 \\
\hline CS-ARWU & 0.046 & 0.0793 \\
\hline NFC & 0.0495 & 0.0854 \\
\hline NSC & 0.0523 & 0.0901 \\
\hline NSP & 0.0573 & 0.0988 \\
\hline NDUCP & 0.0534 & 0.0921 \\
\hline ASS & 0.0531 & 0.0916 \\
\hline TGG & 0.0551 & 0.0949 \\
\hline TTMR & 0.0505 & 0.0871 \\
\hline TRSF & 0.0484 & 0.0834 \\
\hline TUCIR & 0.051 & 0.0879 \\
\hline TOR & 0.0472 & 0.0659 \\
\hline TAER & 0.0382 & 0.0659 \\
\hline
\end{tabular}

In summary, Table 5 demonstrated the measured consequences of ANP hierarchical model of the 20 experts and professionals. 
Table 5. The consolidated evaluated measurements of FA systematic approach and ANP hierarchical model.

\begin{tabular}{|c|c|c|c|c|c|c|c|c|c|}
\hline \multirow[b]{2}{*}{ Criteria } & \multirow[b]{2}{*}{$\begin{array}{c}\text { ANP- } \\
\text { Weights }\end{array}$} & \multirow[b]{2}{*}{$\begin{array}{c}\text { Sub- } \\
\text { Criteria }\end{array}$} & \multirow[b]{2}{*}{$\begin{array}{c}\text { FA- } \\
\text { Weights }\end{array}$} & \multicolumn{2}{|c|}{ NSC } & \multicolumn{2}{|c|}{ PSC } & \multicolumn{2}{|c|}{ PSC } \\
\hline & & & & $\begin{array}{c}\text { ANP- } \\
\text { Weight }\end{array}$ & $\begin{array}{l}\text { Evaluated } \\
\text { Score }\end{array}$ & Weight & $\begin{array}{l}\text { Evaluated } \\
\text { Score }\end{array}$ & Weight & $\begin{array}{c}\text { Evaluated } \\
\text { Score }\end{array}$ \\
\hline \multirow{3}{*}{ USRD } & \multirow{3}{*}{0.0653} & CS-QS & 0.808 & 0.0594 & 0.0031 & 0.2181 & 0.0115 & 0.7225 & 0.0381 \\
\hline & & CS-THE & 0.795 & 0.0635 & 0.0033 & 0.2163 & 0.0112 & 0.7202 & 0.0374 \\
\hline & & CS-ARWU & 0.783 & 0.0703 & 0.0036 & 0.2367 & 0.0121 & 0.693 & 0.0354 \\
\hline \multirow{4}{*}{ ROI } & \multirow{4}{*}{0.2187} & NFC & 0.736 & 0.0631 & 0.0102 & 0.2245 & 0.0361 & 0.7124 & 0.1147 \\
\hline & & NSC & 0.759 & 0.0603 & 0.01 & 0.2233 & 0.0371 & 0.7164 & 0.1189 \\
\hline & & NSP & 0.807 & 0.0587 & 0.0104 & 0.218 & 0.0385 & 0.7233 & 0.1277 \\
\hline & & NDUCP & 0.747 & 0.0592 & 0.0097 & 0.2122 & 0.0347 & 0.7285 & 0.119 \\
\hline \multirow{7}{*}{ HEG } & \multirow{7}{*}{0.716} & ASS & 0.717 & 0.058 & 0.0298 & 0.2051 & 0.1053 & 0.7369 & 0.3783 \\
\hline & & TGG & 0.767 & 0.0621 & 0.0445 & 0.2259 & 0.1241 & 0.712 & 0.391 \\
\hline & & TTMR & 0.756 & 0.0587 & 0.042 & 0.2174 & 0.1177 & 0.724 & 0.3919 \\
\hline & & TRSF & 0.739 & 0.059 & 0.0422 & 0.2159 & 0.1142 & 0.7251 & 0.3837 \\
\hline & & TUCIR & 0.751 & 0.0589 & 0.0422 & 0.2138 & 0.115 & 0.7273 & 0.3911 \\
\hline & & TOR & 0.728 & 0.0576 & 0.0412 & 0.2117 & 0.1103 & 0.7307 & 0.3809 \\
\hline & & TAER & 0.701 & 0.0544 & 0.039 & 0.2062 & 0.1035 & 0.7394 & 0.3711 \\
\hline \multicolumn{5}{|c|}{ Standardized Synthetic Analytical Scale (SSAS) } & 0.0723 & & 0.212 & & 0.7157 \\
\hline
\end{tabular}

In detail, Table 4 not only explained the interactive dependences and correlations between each three analytical perspectives, appraised three criteria, and evaluated 15 subcriteria but also directly expressed the standardized synthetic analytical scale (SSAS) of the consolidated measurements between FA systematic approach of quantitative analysis and ANP hierarchical model of qualitative analysis. As described, the highest SSAS (0.7157) was located at positive sustainability count (PSC), which means these three criteria and 15 subcriteria were directly and positively increase the higher-education sustainability count. The three highest evaluated scores were TTMR (0.3919), TUCIR (0.3911), and TGG (0.391) of HEG based on the consolidation of the commonalities of the FA systematic approach and the pairwise compared weights of the ANP hierarchical model. Significantly, this directly points out the total tuition and miscellaneous revenues (TTMR), total university-industry cooperative revenues (TUCIR), and total grants from government (TGG) have played the most critical roles on sustainable governance performance for higher-education institutions. Combining the commonalities of the FA systematic approach and the pairwise compared weights of the ANP hierarchical model, the highest evaluated score of criteria in USRD was CS-QS (0.0381) which means the assessed comprehensive evaluation of CS-QS does influence the USR developed performance. Continuously, the highest evaluated score of criteria in ROI was NSP (0.1277) which indicates the number of student's publications is the core consideration on the return on investments for higher-education institutions. Ultimately, the highest evaluated score of criteria in HEG was TTMR (0.3919) which points out total tuition and miscellaneous revenues (TTMR) has been the key determinant for higher-education developed sustainability under the shortage of governmental highereducation subsidies.

\section{Conclusions and Recommendations}

This research cross-employed the factor analysis approach and analytical network process hierarchical mode to directly induce the most critical determinants of university environment, social, and governance for higher-education developed sustainability. Therefore, this research has consolidated the 17 SGDs of UN sustainable development of USR, the quantitative measurements of SORI, and the three dimensions of environment, social, and governance of ESG. Furthermore, it also employed, in statistic, the FA systematic approach of quantitative analysis and the ANP hierarchical model of qualitative analysis to evaluate the large-scale questionnaire data from professional experts in order to effectively and efficiently discover the most critical determinants of higher education. As a succession of quantitative and qualitative analyses and measurements, there are four valuable and contributive findings of this research as listed below: 
(1) Total tuition and miscellaneous revenues, total university-industry cooperative revenues, and total grants from government of higher-education governance were able to directly and effectively increase higher-education sustainable value. This definitely indicates that current higher-education students and staff as well as highereducation experts and professionals indeed agree that the tuition and miscellaneous fees, university-industry cooperative, and government grant revenues have become the most critical determinants of university environment social governance. This is because the majority of higher-education institutions do need these revenue resources to advance a succession of environmental protections, social responsibilities and governance performance for current higher-education institution sustainability development.

(2) Comprehensive scale of QS rankings was the most important key determinant to evaluate the university social responsibility development which means the majority of higher-education institutions have to pay more attention on the comprehensive scale of QS rankings in order to make more sustainability count.

(3) Numbers of student's publications was the most crucial key determinant to assay return on investments which means current higher-education students, staff, experts, and professionals consent higher-education institutions have to establish student's publications evaluated system to stimulate students to publish their diversified studying outcomes in order to make students recognize their growth after taking courses in higher education.

(4) Total tuition and miscellaneous revenues was the most momentous key determinant to control high-education governance which means current higher-education students, staff, experts, and professionals concern the various governance performances of their tuition and miscellaneous fees. As for the future direction, there are still some evaluated criteria and assessed methods to be comprehensively considered and employed for inducing in-depth conclusions and findings with higher research reliability and validity without time limitations and resource restrictions.

In terms of research restrictions, the number of interviewees can be increased with more research resources and time. Subsequently, as for the future direction, there are still some evaluated criteria and assessed methods to be comprehensively considered and employed for inducing in-depth conclusions and findings with higher research reliability and validity without time limitations and resource restrictions.

Author Contributions: Conceptualization: M.Y.H.; methodology: Y.-K.C. and M.Y.H.; validation: M.U.; formal analysis: M.Y.H.; investigation: Y.-K.C.; resources: Y.-K.C.; data curation: M.Y.H.; writing original draft preparation: M.Y.H.; writing-review and editing: Y.-K.C., M.Y.H. and M.U.; visualization: Y.-K.C.; supervision: Y.-K.C.; project administration: M.Y.H. All authors have read and agreed to the published version of the manuscript.

Funding: This research received no external funding.

Institutional Review Board Statement: Ethical review and approval were waived for this study, due to all of the interviewees being older than 20 years old and the entire questionnaires being anonymous.

Informed Consent Statement: Informed consent was obtained from all subjects involved in the study.

Acknowledgments: This research was supplied by the research supporting research projects (MOST 110-2420-H-002-003-MY3-Y11017; MOST 109-2221-E-005-049-) of Ministry of Science and Technology and (NTCU109105) of National Taichung University of National Taichung University of Education.

Conflicts of Interest: The authors declare no conflict of interest. 


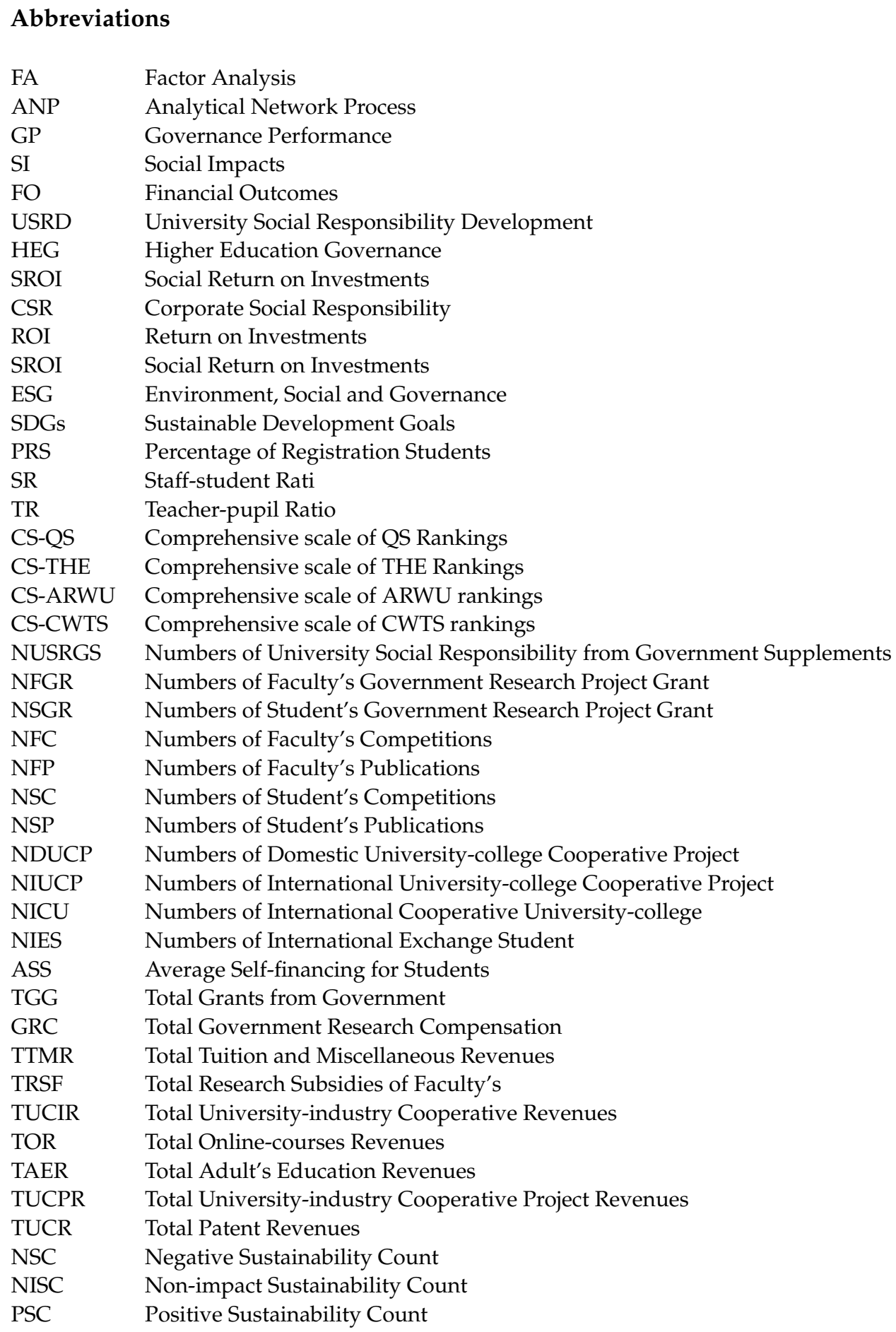

\section{References}

1. Lam, D.A.; Miron, J.A.; Riley, A. Modeling seasonality in fecundability conceptions and births. Demography 1994, $31,321$. [CrossRef]

2. Basu, R.; Malig, B.; Ostro, B. High ambient temperature and the risk of preterm delivery. Am. J. Epid. 2010, 172, 1108. [CrossRef]

3. Cummings, D.R. Human birth seasonality and sunshine. Am. J. Hum. Biol. 2010, 22, 316. [CrossRef]

4. Graff Zivin, J.; Hsiang, S.M.; Neidell, M. Temperature and human capital in the short- and long-run. J. Assoc. Environ. Resour. Econ. 2018, 5, 77. [CrossRef]

5. Huang, Y.-M.; Hsieh, M.-Y.; Usak, M. A Multi-Criteria Study of Decision-Making Proficiency in Student's Employability for Multidisciplinary Curriculums. Mathematics 2020, 8, 897. [CrossRef]

6. Huang, Y.-M.; Hsieh, M.-Y. An Interdisciplinary Research on Students' Employability in Technology Education to Advance Higher Education Enrollment Sustainability. Sustainability 2020, 12, 1806. [CrossRef] 
7. Latif, K.F. The development and validation of stakeholder-based scale for measuring university social responsibility (USR). Soc. Indic. Res. 2018, 140, 511. [CrossRef]

8. Deegan, C. Introduction: The Legitimising Effect of Social and Environmental Disclosures-A Theoretical Foundation. Account. Audit. Account. J. 2002, 15, 282. [CrossRef]

9. Azizul Islam, M.; Deegan, C. Motivations for an Organisation within A Developing Country To Report Social Responsibility Information: Evidence from Bangladesh. Account. Audit. Account. J. 2008, 21, 850. [CrossRef]

10. Bhattacharyya, A.; Cummings, L. Measuring Corporate Environmental Performance-Stakeholder Engagement Evaluation. Bus. Strat. Environ. 2015, 24, 309. [CrossRef]

11. Peiris, D.; Evans, J. The Relationship between Environmental Social Governance Factors and US Stock Performance. J. Investig. 2010, 19, 104.

12. Soderstrom, N. Sustainability reporting: Past, present, and trends for the future. Insights Melb. Bus. Econ. 2013, 13, 278.

13. Hsieh, M.-Y. The most sustainable niche principles of social-media education in a higher education contracting era. Sustainability 2020, 12, 339. [CrossRef]

14. Chen, H.; Nashongka, J.; Donaldson, A. University Social Responsibility (USR): Identifying an Ethical Foundation within Higher Education Institutions. Turk. Online J. Educ. Technol. 2015, 14, 21.

15. Gargani, J. The leap from ROI to SROI: Farther than expected? Eval. Prog. Plan. 2017, 64, 116. [CrossRef]

16. Chang, Y.K.; Oh, W.; Park, J.H.; Jang, M.G. Exploring the Relationship Between Board Characteristics and CSR: Empirical Evidence from Korea. J. Bus. Ethics 2015, 140, 225. [CrossRef]

17. Courtney, P.; Powell, J. Evaluating Innovation in European Rural Development Programmes: Application of the Social Return on Investment (SROI) Method. Sustainability 2020, 12, 2657. [CrossRef]

18. King, N. Making the case for sport and recreation services: The utility of social return on investment (SROI) analysis. Int. J. Public Sector Manag. 2014, 27, 152. [CrossRef]

19. Shafi, M.K. Role of Corporate Social Responsibility in Indian Higher Education: Issues and Challenges. Int. J. Recent Res. Commer. Econ. Manag. 2014, 1, 36-46.

20. Vasilescu, R.; Barna, C.; Epure, M.; Baicu, C. Developing university social responsibility: A model for the challenges of the new civil society. Procedia Soc. Behav. Sci. 2010, 2, 4177. [CrossRef]

21. Chile, L.M.; Black, X.M. University-community engagement: Case study of university social responsibility. Educ. Citizsh. Soc. Justice. 2015, 10, 234. [CrossRef]

22. Plungpongpan, J.; Tiangsoongnern, L.; Speece, M. University social responsibility and brand image of private universities in Bangkok. Int. J. Educ. Manag. 2016, 30, 571. [CrossRef]

23. Gosselin, V.; Boccanfuso, D.; Laberge, S. Social return on investment (SROI) method to evaluate physical activity and sport interventions: A systematic review. Int. J. Behav. Nutr. Phys. Act. 2020, 17, 26. [CrossRef]

24. Maier, F.; Schober, C.; Simsa, R.; Millner, R. SROI as a method for evaluation research: Understanding merits and limitations. VOLUNTAS Int. J. Volunt. Nonprofit Organ. 2015, 26, 1805. [CrossRef]

25. Clementino, E.; Perkins, R. How Do Companies Respond to Environmental, Social and Governance (ESG) ratings? Evidence from Italy. J. Bus. Ethics 2020, 1, 1-19. [CrossRef]

26. de Silva, L.; Chitra, S.; de Silva, K. Emerging Corporate Disclosure of Environmental Social and Governance (ESG) Risks: An Australian Study. Australas. Account. Bus. Financ. J. 2020, 14, 35.

27. Aguilera, R.V. Corporate governance and director accountability: An institutional comparative perspective. Br. J. Manag. 2005, 16, S39-S53. [CrossRef]

28. Lokuwaduge, C.S.D.S.; Heenetigala, K. Integrating environmental, social and governance (ESG) disclosure for a sustainable development: An Australian study. Bus. Strategy. Environ. 2017, 26, 438. [CrossRef]

29. Hsieh, M.-Y. Employing MCDM methodology to verify correlationship between social media and service quality in the dynamic m-commerce era. J. Internet Technol. 2018, 19, 225.

30. Saaty, T.L. How to make a decision: The analytic hierarchy process. Eur. J. Oper. Res. 1971, 48, 9-26. [CrossRef]

31. Saaty, T.L. A Scaling Method for Priorities in Hierarchical Structure. J. Math. Psychnol. 1977, 15, 234-281. [CrossRef]

32. Deren Van Het Hof, S.; Hostut, S. Instrumental, Strategic and Political Conception of Corporate Social Responsibility. Online J. Commun. Media Technol. 2017, 7, 126-146. [CrossRef]

33. Chan, Y.-K.; Hsieh, M.Y.; Usak, M. A Concrete Study on Social-Media Connection of Global Literacy Abilities in MOOCs under the Dual Impacts of Lower Birth-Rate and COVID-19. Sustainability 2021, 13, 2203. [CrossRef] 